desde la academia

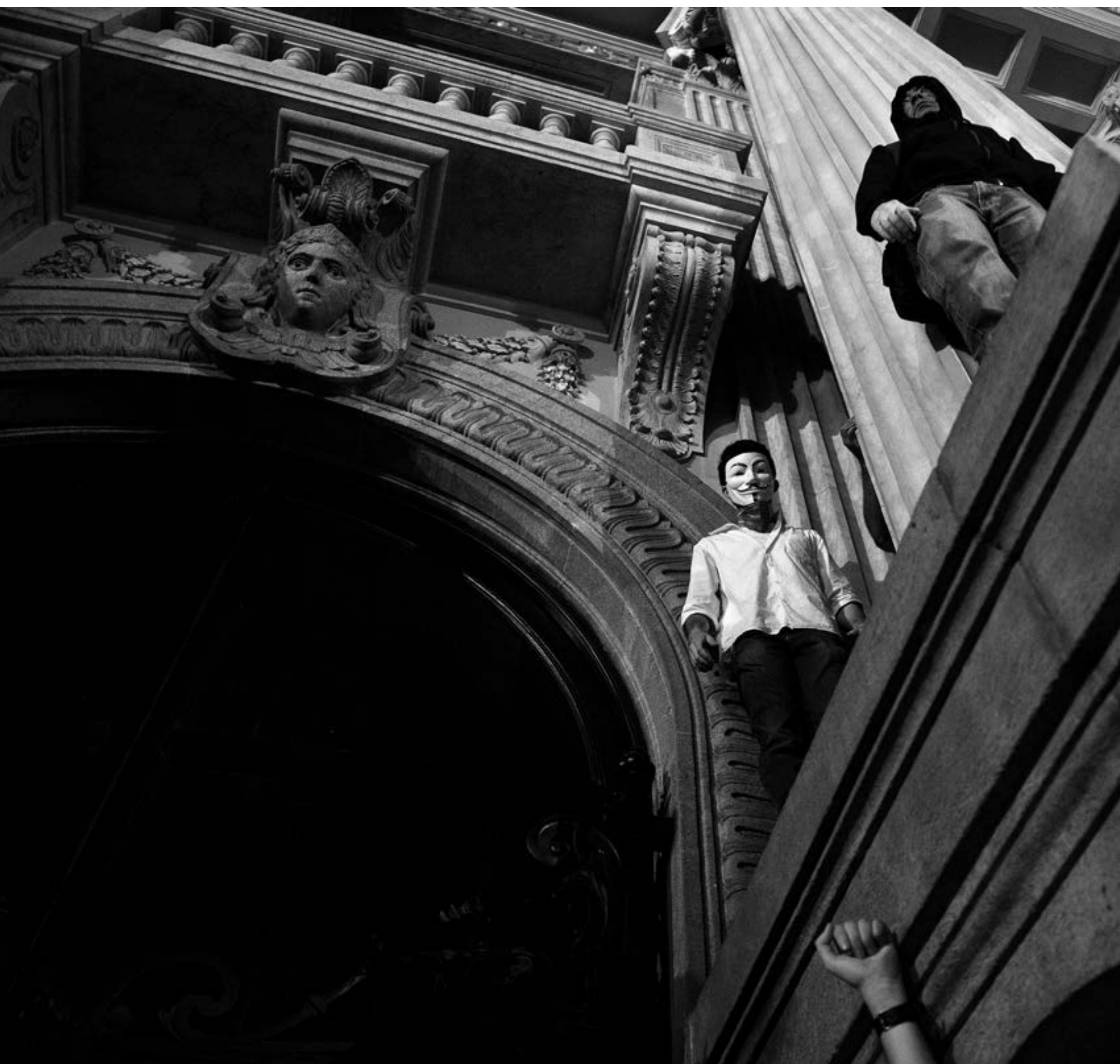




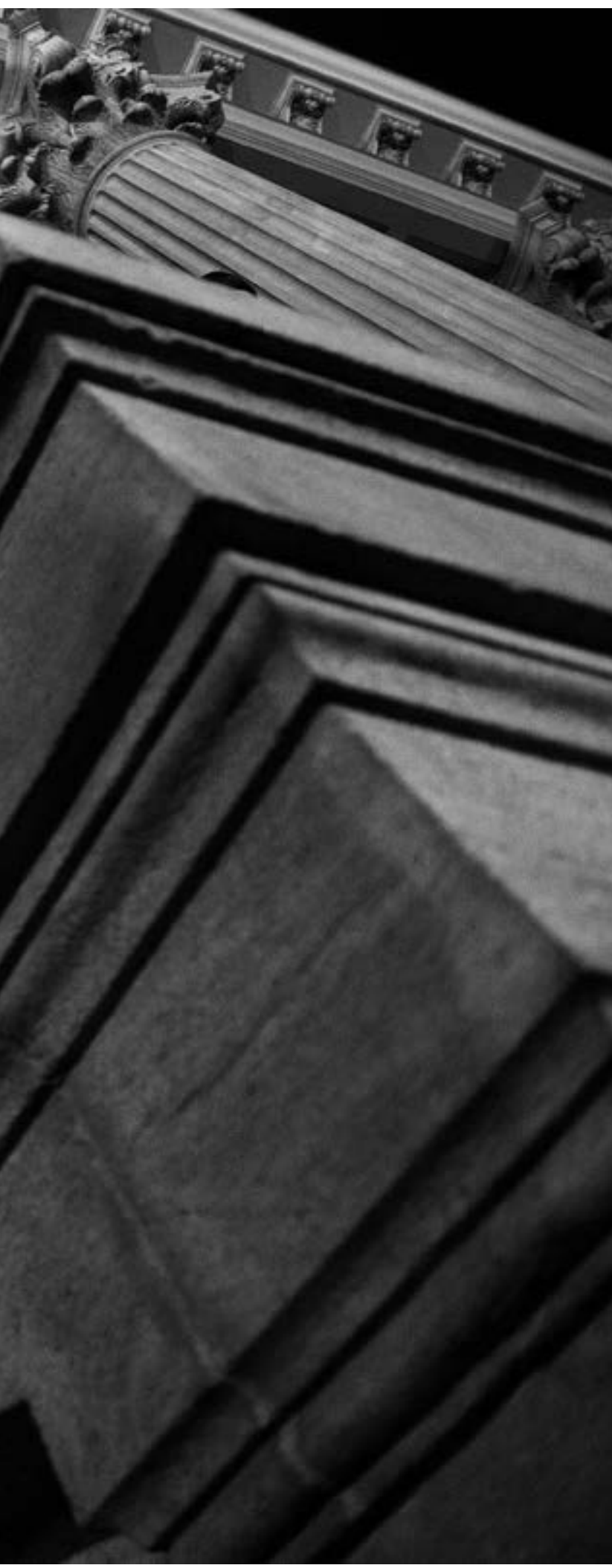

\title{
De la movilización ciberactivista a una biopolítica de las redes
}

\section{From ciberactivist mobilization to a biopolitic in digital networks}

https://doi.org/10.22235/d.v0i25.1269

\author{
Antonino Condorelli y Leticia Gambetta
}

RESUMEN

Este artículo propone la inclusión del concepto de ciberactivismo -que se reduce al uso estratégico de las tecnologías digitales para movilizaciones políticas- en el de biopolítica digital, entendida como producción incesante de lo común en y por las redes. Para operar ese desplazamiento conceptual, se dialoga con las principales concepciones de ciberactivismo y se defiende que, si bien esas visiones ayudan a comprender cómo las redes facilitaron la emergencia de una cultura general de la movilización, no problematizan las posibilidades de captura de las propias movilizaciones en red, ni la existencia de un activismo digital de carácter reproductor/conservador. Se plantea entonces la idea de una biopolítica digital para pensar las manifestaciones como posibilidades que emergen de un proceso inmanente de producción de lo común en las redes. Para sustentar esta idea, se analizan las estrategias de dos movimientos sociales brasileños.

Palabras clave: ciberactivismo, biopolítica, redes digitales, movimientos sociales, estrategias

\section{ABSTRACT}

This article proposes the inclusion of the concept of 'cyberactivism' -which is reduced to the strategic use of digital technologies for political mobilizations - in that of 'digital biopolitics' understood as incessant production of the common, in and through networks. In order to operate this conceptual displacement, the main concepts of cyberactivism are discussed and it is argued that, although these visions help to understand how the networks facilitated the emergence of a general culture of mobilization, they do not problematize the possibilities of catching the mobilizations own network, nor the existence of a digital activism of a reproductive/conservative nature. Thus, this paper presents the idea of a digital biopolitics to think of manifestations as possibilities that emerge from an immanent process of production of the common in the networks. To support this idea, the strategies of two Brazilian social movements are analyzed.

Keywords: cyberactivism, biopolitics, digital networks, social movements, strategies
Antonino Condorelli Universidade Federal do Rio Grande do Norte Natal, Brasil condor_76@hotmail.com

Leticia Gambetta Universidade Federal do Rio Grande do Norte Natal, Brasil

leticiagambetta@gmail.com

Recepción: octubre 2016 Aceptación: noviembre 2016

Foto: ${ }^{\circ A F P / P a b l o ~}$ Porciúncula. Protesta por el millonario gasto en la Copa de las Confederaciones y los preparativos para el Mundial de Fútbol. Rio de Janeiro, junio de 2013 
$1::$ Se entiende por dominación -con base en la interpretación deleuziana del pensamiento de Foucault sobre dispositivos (Deleuze, 2015)- la capacidad de predeterminar aquello que las subjetividades pueden tener como experiencia: conocer, pensar, decir y hacer.

2:: Deleuze entiende

la singularidad como preindividual, impersonal y "aconceptual": una virtualidad inmanente. El ser se constituye así como un campo de singularidades en sus agenciamientos y re-combinaciones: virtualidad que produce relaciones diferenciales y solo es divisible en las diferencias que lo expresan. Negri y Hardt (2005) refieren

a singularidades en

cooperación apuntando a individualizaciones especificas, personales o colectivas, de singularidades en la acepción deleuziana: expresiones de diferencia pura.
Multitud y biopolítica en las redes digitales Este trabajo se coloca ante un problema teórico y político: ¿cómo pensar y practicar una biopolítica en y por las redes digitales de comunicación distribuida? Aquí se entiende biopolítica en el mismo sentido que Negri y Hardt (2005), quienes reinterpretan el concepto foucaultiano como movilización productiva de todo el mundo de la vida (cuerpo, cognición, afectos, lenguaje) para ampliar la potencia de autogobierno en la inmanencia de la constitución de lo común, y reducir al mínimo posible los mecanismos de dominación ${ }^{1}$.

Negri (1993) adopta la noción spinoziana de potencia como capacidad de existir y de actuar, que puede ser ampliada o refrenada por los tipos de relaciones que las singularidades en interacción establecen entre sí. Malini y Antoun (2013) sintetizan la concepción negriana de biopolítica, que se contrapone al biopoder -concepto tomado también de Foucault- entendido como proceso de captura-cercenamiento-regulación externa de la potencia vital:

La biopolítica es la potencia de la vida de gobernarse a sí misma, los "espacios en los cuales se desarrollan luchas, relaciones y producciones de poder"; y el biopoder, un poder contra la autonomía de la vida, buscando hacerla someterse a centros trascendentes de gobierno (Malini y Antoun, 2013, p. 175).

Biopolítica, en esta acepción, es la producción incesante de lo común. Negri (2005) diferencia lo común de lo público -porque presupone un recorte del flujo de la existencia en esferas separadas y delimitadas (público/privado, individual/colectivo) y una dimensión contractual que impone una predefinición abstracta, esto es, la trascendencia a un proceso de producción del mundo incesante e inmanente- $y$ lo concibe como movimiento: construcción de las condiciones compartidas de la existencia por la comunicación y cooperación entre singularidades ${ }^{2}$.
Tanto la biopolítica como lo común presuponen apertura, disposición para compartir, cooperación entre singularidades que no se niegan o excluyen mutuamente: por lo tanto, implican la negación de cualquier reducción a narrativas unitarias, identitarias y excluyentes. Para concebir una biopolítica en y por las redes digitales es preciso pensar en un sujeto colectivo que construya lo común en las interacciones digitales. Para ese fin, el concepto de multitud elaborado por Negri y Hardt (2005) aporta perspectivas fecundas.

Multitud no es sinónimo de masa: es un sujeto biopolítico colectivo que Negri (2004; Negri y Hardt, 2005) conceptualiza como cooperación de singularidades que expresan una inmanencia (no reductible a unidades abstractas que trascienden lo concreto de sus singularidades), una dimensión de clase (una realidad productiva, en devenir incesante, explotada en el conjunto de sus singularidades) y una potencia (un todo que produce más allá de la suma de sus singularidades, y se expande como intelecto general: una cognición colectiva cooperativista).

Multitud es un concepto que trasciende a la dimensión clásica del trabajo asalariado, rechaza la dicotomía moderna entre trabajo manual (o material) e intelectual -al rearticular cuerpo y mente en la idea de trabajo inmaterial ${ }^{3}$ - y hace referencia "a las capacidades creativas humanas en toda su generalidad" (Negri y Hardt, 2005, p. 145), lo que abarca tanto a los excluidos del proceso productivo como a "los innúmeros y específicos tipos de trabajo, formas de vida y ubicación geográfica” (p. 146) en un proyecto de construcción cooperativa de lo común.

Por lo tanto, pensar en una biopolítica digital implica concebirla como singularidades que cooperan, cuerpos que movilizan afectos, conocimientos y lenguajes para producir, reproducir y colocar en circulación conocimientos y formas de vida, mediante tecnologías digitales de comunicación. 


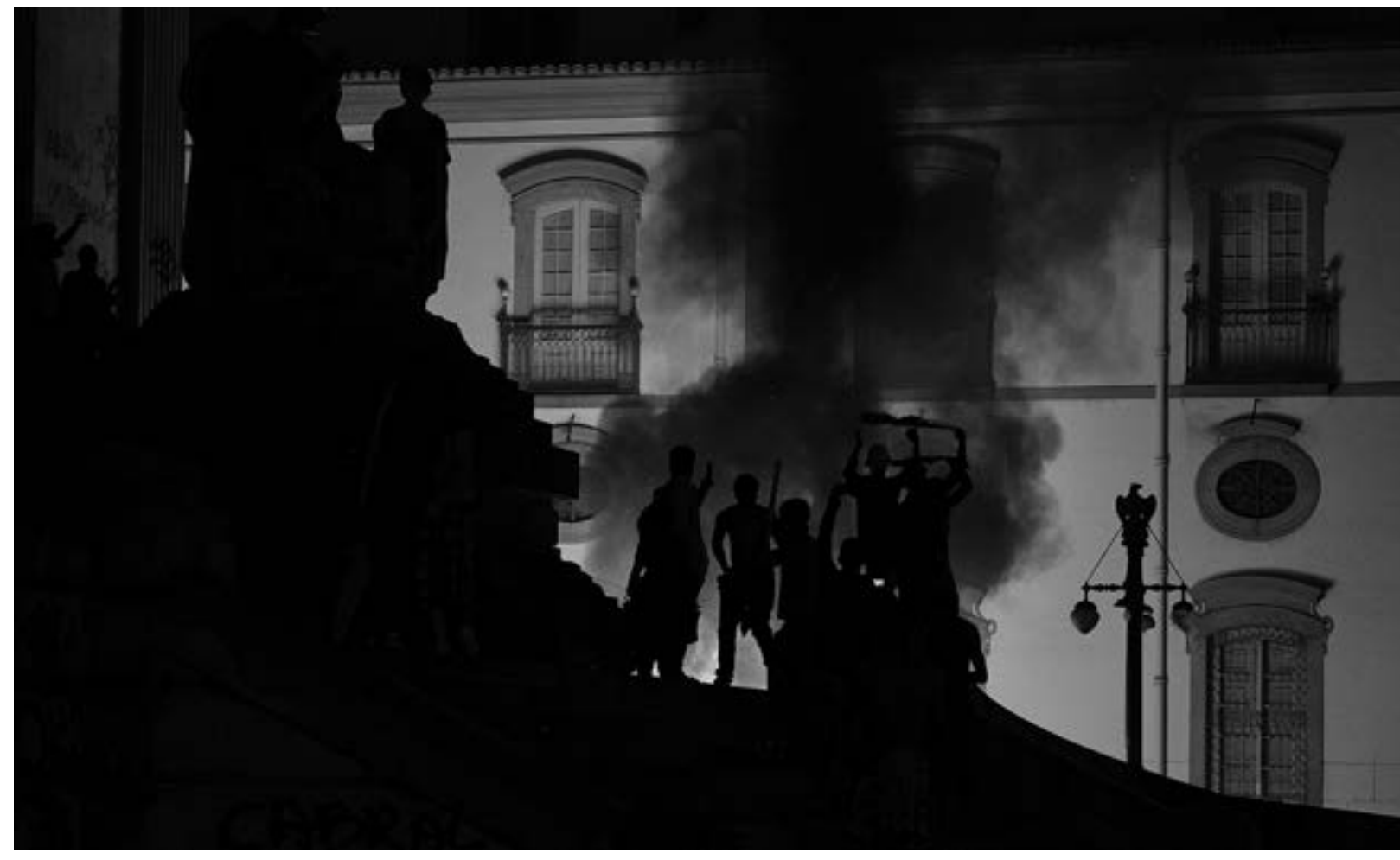

Foto: ${ }^{\oplus A F P} /$ Pablo Porciúncula. Protesta frente a la Asamblea Legislativa de Río de Janeiro, junio de 2013

En esa incesante producción-reproducción-circulación se pueden producir, de manera colaborativa, conocimientos y formas de vida que sean mínimamente capturados, es decir, que no reproduzcan presupuestos conceptuales y discursivos, prácticas, relaciones de control y de dominación.

Se trata de singularidades conectadas en redes digitales de comunicación distribuida y en redes sociotécnicas metropolitanas (y, con menos intensidad, no urbanas) de transporte, vivienda, educación, salud. Redes que se compenetran, cruzan, atraviesan a lo largo de líneas de fuerza - de visibilidad y de enunciación- que configuran lo visible y lo decible, al tiempo que trazan líneas de fuga y procesos de subjetivación ${ }^{4}$ que, al reorganizar las determinaciones dispuestas, escapan a los saberes $\mathrm{y}$ poderes que las recorren y moldean.

En estas redes hierve una re-producción cooperativa permanente, donde singularidades personales o de grupo -que se mantienen como tales- hacen circular ideas, sentidos, estilos de vida, narrativas, técnicas y saberes, y los reconfiguran, moldean, adaptan, transforman en una incesante danza antropofágica en la cual la "escasez es sustituida por la abundancia; la valorización se desplaza de la producción para la propia transacción (circulación), la rivalidad entre los bienes (es decir, la exclusividad del consumo) da lugar al compartir" (Cocco, 2009, p. 138). Se configura un $h_{a c k e o^{5}}$ social, tecnológico y cultural incesante,
3:: Para Negri y Hardt (2005) no es sinónimo de trabajo intelectual, sino que envuelve y religa cuerpo y mente en el proceso de producción y reproducción de la vida: "Tal vez sería mejor entender la nueva forma hegemónica como 'trabajo biopolítico', o sea, trabajo que crea no solo bienes materiales, sino también relaciones $y$, en último análisis, la propia vida social" (p.150).

4:: Se usa aquí subjetivación para indicar los procesos que contribuyen a la construcción de subjetividades por la acción de redes de prácticas y mecanismos de saber y poder. Se enfatiza la ausencia de determinismos: las subjetividades se construyen en el interagenciamiento, lo que deja margen para la autoconstrucción y la autovaloración. Según las condiciones de agenciamiento, esa construcción puede ser reproductora (de mecanismos de podersaber) o productora (de diferencia).

5:: Se emplea el término en el sentido de reapropiación, resignificación/reinvención y redefinición de lógicas y modos de uso de un producto (material 0 intangible) o fenómeno socio-tecno-cultural. 
6:: Esas redes se conciben como telas

de interacciones

que emergen del

acoplamiento de sujetos con tecnologías digitales de producción, divulgación,

almacenamiento y reproducción de signos (computadoras, laptops, celulares, tablets) conectadas en redes de telecomunicaciones, con flujos de interacción simultánea y pluridireccional; con los lenguajes que esas tecnologías posibilitan (hipertexto,

imagen, audio, video, animación, lenguajes de programación)

y sus convergencias.

7:: La literatura sobre ciberactivismo define la práctica de swarming como la autocoordinación en redes digitales, sin centros ni jerarquias, de grandes cantidades de personas que afluyen de manera aparentemente

espontánea a uno o varios lugares, como

forma de presión política sobre determinados temas (Padilla, 2012). en que el momento de la socialización es más importante que el de la producción, en que el proceso es más importante que los productos y en que el gozo es simultáneo a la realización.

Ese proceso de producción, circulación y consumo incesante, que moviliza todas las dimensiones de la existencia y abarca todo el tiempo de vida, hoy se desarrolla enteramente dentro de redes sociales - esto es, redes de intercambio y del compartir- que hibridan cuerpos, mentes y tecnologías digitales de comunicación. Es decir, las redes sociales contemporáneas, en buena parte, se estructuran hoy dentro de redes digitales de comunicación distribuida. ${ }^{6}$

\section{Ciberactivismo y movimientos sociales en red}

La relación sujetos-tecnologías que permea y funda las redes las configura como un terreno político (Malini y Anotun, 2013; Rüdiger, 2011) de producción de subjetividad, donde se confrontan intereses, poderes, concepciones del mundo, prácticas materiales, simbólicas y discursivas, imaginarios, saberes, paradigmas de construcción de conocimiento e inteligibilidad de lo real, proyectos sociales, económico-políticos, científico-tecnológicos, militares, religiosos y culturales.

Una tendencia que parece impregnar la mayoría de los usos actuales de las redes digitales es lo que Bentes (2013) describe como "la emergencia de una economía de la abundancia, del compartir” (p. 11). De hecho, es posible constatar que la mayoría de los sujetos conectados incesantemente producen y comparten mensajes, intercambian ideas, puntos de vista, saberes, afectos, generan de forma colaborativa y socializan conocimientos, narrativas, software, acciones. Todo el tiempo, y en casi todo lugar, singularidades conectadas cooperan creando una abundancia de conocimientos y formas de vida, y comparten los productos de esa cooperación de forma gratuita.
A partir de esa constatación, el imaginario hegemónico entre los usuarios de Internet y algunas corrientes de pensamiento social y comunicacional contemporáneas (Castells, 2013; Malini y Antoun, 2013; Da Silveira, Braga y Penteado, 2014) asocian la lucha por la autonomía y la autovaloración de las subjetividades en red a las movilizaciones de individuos y grupos conectados -ya sea esporádica y espontáneamente autoorganizados o previamente estructurados- en torno a causas políticas, socio-tecno-culturales, ambientales. Esa asociación provocó el surgimiento y la rápida diseminación -entre internautas y pensadores de lo digital (Silveira, 2012; Da Silveira, Braga y Penteado, 2014)- del concepto de ciberactivismo, para concebir un conjunto amplio y heterogéneo de prácticas. Estas prácticas van desde la creación de medios de comunicación - para producir y difundir informaciones y narrativas alternativas a las ofrecidas por medios comerciales- hasta el surgimiento de movimientos espontáneos de movilización distribuida.

Estos últimos, asimismo, abarcan desde la creación de coaliciones temporarias sobre causas específicas en comunidades virtuales hasta campañas organizadas en torno de centros responsables por la definición de estrategias y objetivos, concepción de acciones y difusión de informaciones; desde ataques de hackers a sitios, servidores o sistemas informáticos de corporaciones, bancos, instituciones gubernamentales y otras organizaciones hasta el swarming o enjambre ${ }^{7}$; desde la construcción colaborativa de software de código abierto, sistemas de criptografía, principios y lógicas alternativas a las dominantes hasta el simple uso de perfiles personales en sitios de redes sociales para difundir pedidos o sensibilizar causas.

Las prácticas sociales y políticas digitales se producen en la red a través de múltiples emisores. En este trabajo se propone una categorización de esos enunciadores que utilizan el escenario digital para soltar la voz. 


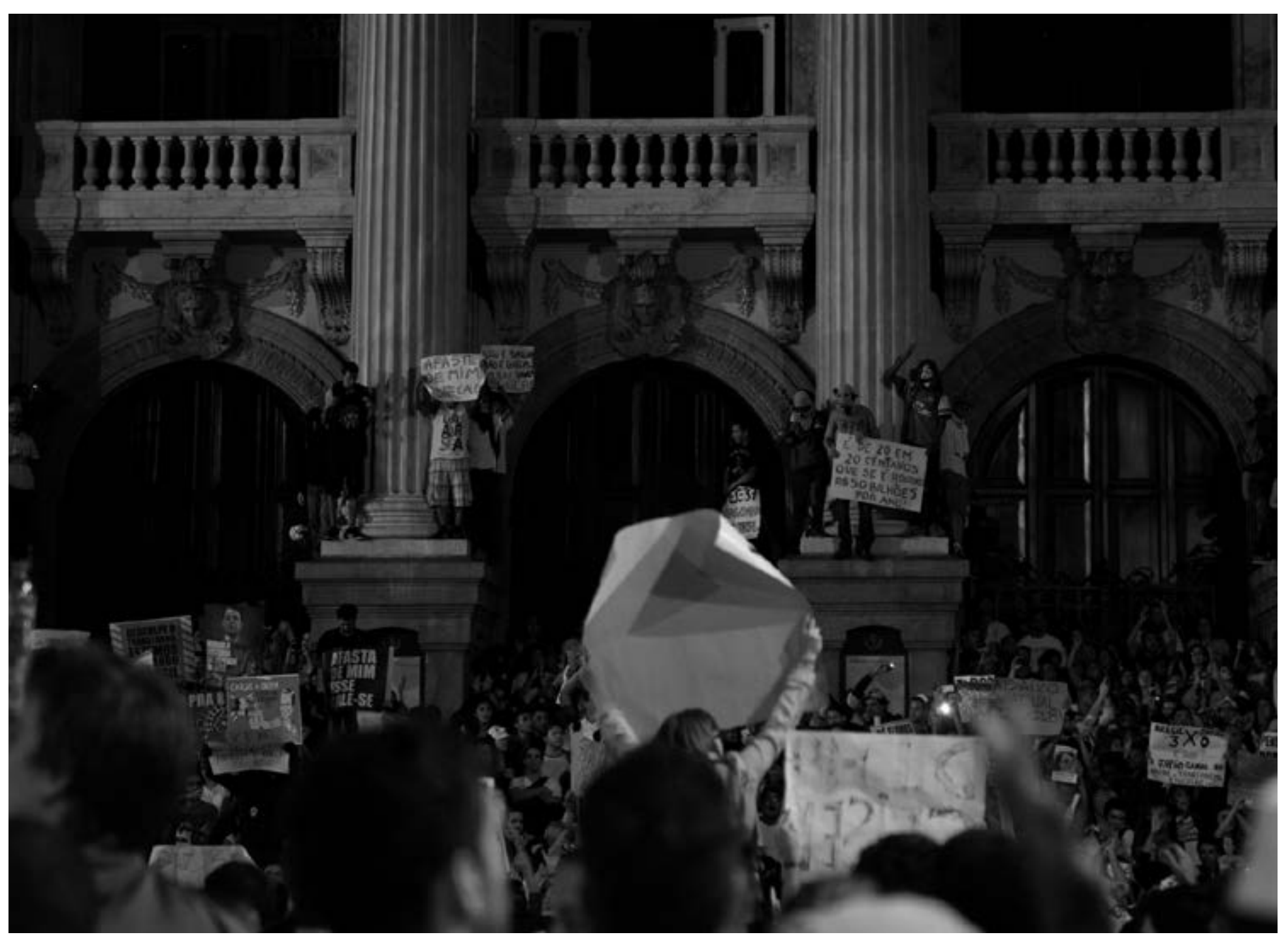

Prácticas políticas en red y dispositivos

Por un lado, se puede considerar la tendencia general a la movilización en el ámbito de una sociedad inmersa en un "devenir cyborg", tal como establece Toret (2012). Esto es:

En el contexto de una transformación vertiginosa de los hábitos sociales y subjetivos ocasionada por la profunda socialización de los mundos digitales interactivos, y plena de nuevas capacidades que los cerebros y máquinas en red pueden expresar. La sociedad red vislumbra nuevas formas organizativas y de contrapoder gracias al crecimiento de las capacidades tecnopolíticas de las multitudes conectadas, y a la emergencia de nuevas formas de organización, inteligencia y acción colectiva (p. 139).

Por otro lado, sin embargo, una observación empírica de la realidad contemporánea no tardará en constatar que esas capacidades tecnopolíticas de las multitudes conectadas (el uso estratégico de las tecnologías digitales de comunicación para hacer emerger nuevas formas de organización y acción colectivas) no promueven necesariamente -como si fuera una lógica inherente a su aparición - un aumento de la potencia de vida,
Foto: ${ }^{\odot A F P} /$ Pablo Porciúncula. Rio de Janeiro, junio de 2013 
sino que, como ha ocurrido con mucha más frecuencia y con intensidad mucho más fuerte, pueden ser re-productoras de prácticas, acciones y discursos drásticamente cercenadores, cuando no brutalmente castradores de la capacidad de individuos y grupos de existir y de actuar. Morozov (2011) muestra que, en muchos países, las redes digitales han sido y son usadas para organizar movimientos xenófobos, racistas, homo y transfóbicos, de persecución religiosa, política y de otros tipos, así como para promover acciones colectivas violentas contra inmigrantes, homo y transexuales, mujeres, practicantes de determinadas religiones, militantes políticos.

Esas nuevas capacidades que los cerebros y máquinas en red pueden expresarvan entonces desde la organización de movimientos o acciones contra la construcción de usinas hidroeléctricas en tierras indigenas en la Amazonia o la ocupación militar de favelas en Río de Janeiro hasta el reclutamiento de militantes por parte de la organización terrorista transnacional Estado Islámico o por grupos neonazis europeos; desde la promoción de campañas por el desarme hasta la de campañas por la expulsión de inmigrantes o la reducción de la mayoría de edad penal; desde la movilización por la ampliación de los espacios institucionales de participación social hasta movilizaciones por el retorno de la dictadura militar.

Todas esas prácticas son producto de una cultura general de la movilización que impregna la configuración actual de las redes digitales, y todas ellas manifiestan usos estratégicos de las tecnologías de comunicación para la organización y la acción colectivas en torno a determinadas causas. Todas ellas expresan capacidades de inteligencia colectiva que emergen de la interacción de singularidades en red. Todas, por lo tanto, pueden ser consideradas formas de ciberactivismo -en el sentido impreso al término por la mayoría de los autores que reflexionan sobre el concepto-, sintetizado por la idea de Toret (2012) de un uso estratégico de las redes digitales de comunicación distribuida por parte de individuos y grupos para organizarse y actuar en colectivo, en el ámbito de una tendencia general a la movilización horizontal. Todas son prácticas ciberactivistas. No todas, sin embargo, son biopolíticas.

En otro orden, aun cuando prácticas y acciones de movilización individual y colectiva en y por las redes digitales revisten fines emancipadores de autogobierno y aumento de la potencia de la vida, el uso de las tecnologías con tales objetivos no necesariamente está libre de mecanismos o procesos de captura.

Considérense actitudes como el compartir instantáneo y sin reflexión de imágenes, sonidos y palabras, provocado por una afectación emocional inmediata; la búsqueda de vínculos comunitarios efímeros, que no cubren compromisos duraderos ni un involucramiento constante en determinados proyectos o causas; la expectativa por resultados inmediatos o de corto plazo de las acciones realizadas en el medio digital; la fragmentación de la atención en recorridos de lectura/recepción hipermediáticos y en la realización simultánea de múltiples tareas; la conexión compulsiva que estimula y genera intercambios (a menudo muy intensos) por la mera interacción, sin producción de transformaciones en las subjetividades conectadas; la concentración de las interacciones digitales alrededor de hubs (ejes o centros de distribución), que reinserta elementos de verticalidad, jerarquización y concentración de poder y saber en telas de comunicación supuestamente horizontales y distribuidas; el "gerenciamiento de sí" en el sentido mercadológico de construcción de estrategias para despertar el interés de otros sujetos conectados hacia los mensajes y narrativas producidas por un polo emisor, y el "compromiso" como condición para "posicionarse" y permanecer "visible" en las redes; entre otras lógicas de uso de o interacción con las tecnologías digitales de comunicación ampliamente diseminadas entre los internautas de muchos países. 
Muchas de esas lógicas permean prácticas y acciones de movilización en y por medio de redes digitales que tienen objetivos biopolíticos. Este análisis opera en ellas y en las acciones que producen mecanismos de regulación propios de los dispositivos de las corporaciones 2.0.

Desde el punto de vista del capital, la captura es operada por la cuantificación arbitraria del valor social (conocimientos y formas de vida) creado por las interacciones digitales de los usuarios, por parte de las corporaciones que gerencian motores de búsqueda o redes sociales y traducen el valor socialmente producido en lucro. Para que esa metrificación de las interacciones digitales ocurra, las corporaciones gerenciadoras de los mecanismos de acceso a las redes digitales incentivan la interacción, la producción colaborativa de conocimientos, informaciones, narrativas, modos de relación, emociones individuales y colectivas con base en lógicas funcionales a sus intereses de cuantificación para la generación de lucro a partir de la producción inmaterial social.

Las interfaces elaboradas para facilitar y tornar cada vez más "amigable”, intuitiva y ágil la interacción de los sujetos en red con los aparatos y con los demás sujetos conectados; las posibilidades inmediatas de interacción que esas interfaces permiten y estimulan -al agenciarse con subjetividades que muchas veces se perciben como aisladas- son despolitizadas, caracterizadas por múltiples intereses y no responden a un incentivo que tienda a la autopercepción de sus tendencias de pensamiento y acción.

Estas son lógicas pautadas por la velocidad -en detrimento de la profundidad-de re-producción, de recepción (afectación cognitiva, afectiva, corporal) y del compartir; por la búsqueda de vínculos frágiles basados en afinidades emotivas temporarias; por la dispersión de la atención; por la re-producción de flujos de comunicación verticalizados; por el gerenciamiento mercadológico de la representación de sí, entre otros.
Se trata de lógicas que atraviesan y configuran innumerables prácticas y acciones, producto de la movilización de individuos y grupos con independencia de sus fines $\mathrm{y}$, aún más, de sus contenidos (mensajes, narrativas, conocimientos compartidos).

Las lógicas de interacción en red reproductoras de líneas de fuerza del dispositivo de control descripto se entrañan en los cerebros y los cuerpos, estructurando sinapsis y originando hábitos -cognitivos, perceptivos, emocionales, relacionales- $\mathrm{y}$ automatismos.

El poder se ejerce, ahora, por máquinas que organizan directamente los cerebros (por sistemas de comunicación, redes de informaciones, etc.) ylos cuerpos (por sistemas de ventajas sociales, actividades desarrolladas, etc.) en dirección a un estado de alienación autónoma, partiendo del sentido de la vida y del deseo de creatividad. [...] Ese control se extiende mucho más allá de los espacios estructurados de las instituciones sociales, por intermedio de redes flexibles, modulables y fluctuantes. [...] El poder se exprime, así, como un control que invade las profundidades de las conciencias y de los cuerpos de la población $-\mathrm{y}$ que se extiende, al mismo tiempo, a través de la integralidad de las relaciones sociales (Negri y Hardt, 2010, p. 163).

Prácticas ciberactivistas con motivaciones biopolíticas y fines emancipadores, por lo tanto, no están exentas de la re-producción de relaciones de dominación, que se ejercen y expresan en determinadas lógicas de usos de las redes digitales, en determinados comportamientos $\mathrm{y}$ en los hábitos sensoriales, perceptivos, cognitivos, emocionales y relacionales que los sustentan. No es posible, por lo tanto, asociar automática y necesariamente lo que muchos usuarios de Internet y varios autores llaman ciberactivismo con un uso biopolítico de las redes digitales. 


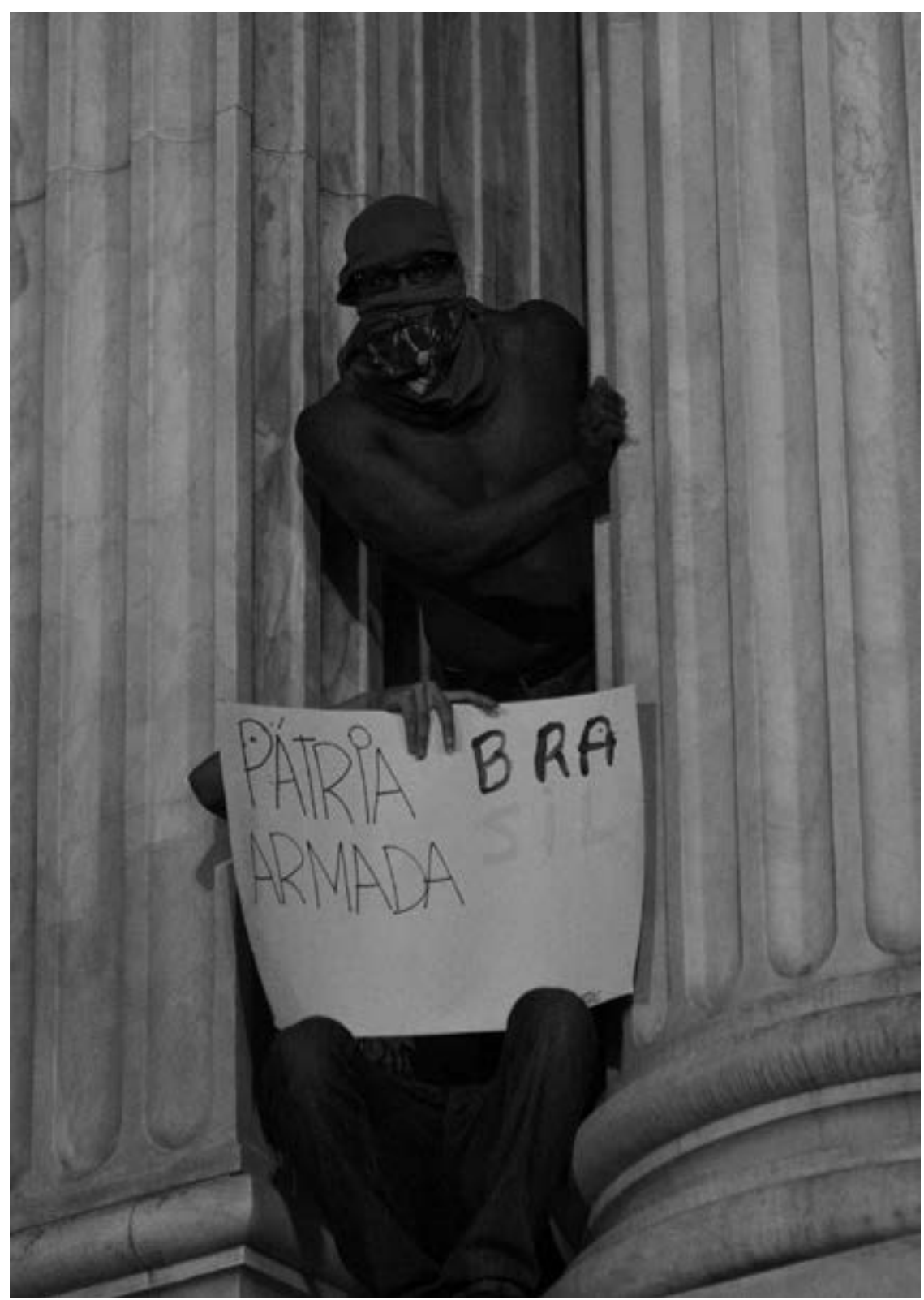

Foto: ๑AFP/Pablo Porciúncula
Este análisis considera al ciberactivismo, además de todo, como un concepto reductivo: a pesar de abarcar un amplio espectro de prácticas, crea para las movilizaciones y acciones políticas en y por las redes un lugar específico, separado de la cooperación-colaboración, del compartir (conocimiento y formas de vida) permanente del trabajo vivo. 0 sea, produce cajas y subcajas que introducen trascendencia (abstracciones configuradoras que predefinen y moldean los fenómenos que pretende "recubrir"), rigidez y separaciones en un devenir incesante, abierto y totalmente inmanente de la producción cooperativa de informaciones, conocimientos, poderes/saberes, discursos, prácticas.

Los conceptos son agenciadores: hablar de ciberactivismo instituye una separación entre unas actitudes activas y otras supuestamente pasivas en las redes, un universo en que todas las subjetividades interconectadas que cooperan son, de formas diferentes, productoras o reproductoras - por lo tanto, agentes activos- de conocimientos y formas de vida.

Análisis contrastivo entre movimientos ciberactivistas para pensar una biopolítica digital Para ilustrar la convergencia entre lógicas y modos de subjetivación entre diferentes tipos de prácticas ciberactivistas, ya sea con contenidos libertarios o conservadores, se analizan dos movilizaciones surgidas en redes digitales en Brasil, que provinieron de lugares muy diferentes de convocatoria.

Ambas tienen en común su línea de acción discursiva, tendiente a criticar gestiones de gobierno y estimular la movilización de sus seguidores (y la utilización para esos fines, prioritariamente, de recursos virtuales). Se trata de los movimientos Fora Micarla y Vem pra rua, ambos protagonistas de acciones de oposición política en Brasil. 
El movimiento Fora Micarla tuvo una acción local en la ciudad de Natal, capital del Estado de Río Grande del Norte. Se formó en 2011, principalmente por jóvenes universitarios que, desde sus primeras acciones, pedían el impeachment de la intendenta Micarla de Sousa debido a importantes irregularidades en la gestión municipal. Las redes sociales fueron un elemento clave, tanto para la formación del movimiento como para su organización, y al mismo tiempo como principal vía de convocatoria para la movilización, ya fuera virtual o presencial.

La presión fue tan intensa que el Fora Micarla consiguió sensibilizar a la sociedad, movilizar a varios sectores y obligar al poder político a asumir compromisos concretos que ofrecieran alguna respuesta a sus reivindicaciones. El movimiento no logró su objetivo principal, que era apartar a la intendenta de su cargo, pero algunos reclamos fueron efectivamente considerados, como la implantación de una comisión investigadora de contratos irregulares firmados por la intendencia.

Fora Micarla surgió espontáneamente entre jóvenes natalenses, se caracterizó por su carácter horizontal, sin liderazgos definidos, y de corte progresista. Su objetivo era el de luchar contra el poder establecido, al que calificaban de ostentador de privilegios y de impunidad. Esas banderas estaban reforzadas por el hecho de que la intendenta era periodista y dueña de unos de los principales canales de televisión, repetidora local de la cadena SBT.

En el otro extremo está el movimiento Vem pra rua -con acción articulada en todo el territorio nacionalque se posiciona como contrario a cualquier forma de corrupción y se autodefine en su página oficial como un "movimiento suprapartidario, democrático y plural que surgió de la organización espontánea de la sociedad civil para luchar por un Brasil mejor" (Vem pra rua, s. f.). Vem pra rua surgió en 2014, tras una serie de manifestaciones masivas ocurridas contra la corrupción ${ }^{8}$ durante la Copa de las Confederaciones en casi todo el territorio nacional. La iniciativa se "apropió" de esta insatisfacción colectiva junto a otros movimientos de ideología similar (como el Movimiento Brasil Libre) y comenzó su articulación bajo la bandera de lucha contra la corrupción generalizada. A partir de ese momento, y en una política discursiva cuidadosa, Vem pra rua fue adhiriendo a diversas causas hasta abrazar la defensa del impeachment a Dilma Roussef. Esta bandera fue defendida con todos los recursos posibles y apelando a varias líneas estratégicas muy bien planeadas y ejecutadas. El camino discursivo recorrido por Vem pra rua acabó por mostrar el verdadero objetivo de sus dirigentes: sacar al Partido de los Trabajadores del poder.

Vem pra rua se ha caracterizado por desarrollar una estrategia mediática altamente articulada. Es un movimiento que cuenta con un sitio web, página de Facebook, cuentas de Instagram y Twitter; canales que se mantienen permanentemente actualizados. Vem pra rua invierte también en medios tradicionales de comunicación, como fue el caso de las campañas de Outdoor realizadas en varias ciudades de Brasil. Existe también una línea de productos de merchandising, principalmente camisetas, con diseños en consonancia con la identidad visual del movimiento.

La agrupación ha apelado a los símbolos patrios como recurso identitario. Toda su comunicación visual refuerza el verde amarelo $^{9}$ : en las manifestaciones presenciales se convoca a llevar la camisa de la selección brasileña y la bandera del país ha sido apropiada como símbolo de lucha, al exaltar el patriotismo como "salvación” del país. El movimiento tiene dirigentes definidos que se identifican como líderes y son los
8:: Las primeras manifestaciones en realidad surgieron en reclamo por el aumento del precio del boleto en San Pablo, pero se fueron extendiendo a todo el pais y levantando la bandera contra la corrupción en un período de especial sensibilidad por la inminente celebración del Mundial de Fútbol.

9:: Colores de la bandera de Brasil y una denominación utilizada en diversos contextos para referirse a Brasil y a sus habitantes. 
responsables de hablar en su nombre en los diferentes canales. Aun con las semejanzas mencionadas entre ambos movimientos, las diferencias son importantes. Se elaboró un cuadro comparativo simple para plasmar de manera más gráfica estas observaciones (ver tabla).

Para realizar la comparación entre ambos movimientos se contó con el apoyo teórico y metodológico del análisis crítico del discurso, a través de los trabajos de Fairclough (2001, 2003), y de la lingüística sistémico funcional, más específicamente del sistema de evaluación propuesto por Martin y White (2005) que permite evidenciar el posicionamiento del hablante/escritor en determinado contexto, mostrar su neutralidad o posicionamiento al aceptar o rechazar el posicionamiento del otro y, finalmente, explicar qué recursos dialógicos son utilizados para crear relaciones interpersonales entre hablante/escritor y oyente/lector.

Una mirada atenta a las principales características de los dos movimientos revela que -más allá de las significativas diferencias entre sus estrategias de articulación, los objetivos y valores compartidos por sus participantes y sus formas de liderazgo-existe un hilo común que los atraviesa y que no se reduce al hecho evidente de que ambos utilizan a las redes sociales como principal instrumento de comunicación interna y externa.

Ese hilo se relaciona con su modo común de afectación: el contagio viral de emociones que se despliega entre las redes digitales y el contacto corporal en las calles (o, en el caso de Fora Micarla, en el espacio público ocupado), y que es promovido a través de la diseminación de mensajes hipertextuales multimodales -esto es, construidos entrecruzando elementos procedentes de distintos lenguajes y distintos registros de un mismo lenguaje-con una fuerte capacidad de afectación emocional instantánea. 0 sea, ambos movilizan personas a través de la creación de ambientes afectivos construidos por una comunicación que apela a la emoción y que estimula una reacción inmediata, que la interactividad de las redes hace posible gracias a la capacidad de circulación de esos afectos que ellas propician.

\begin{tabular}{|c|c|c|}
\hline \multicolumn{3}{|c|}{$\begin{array}{c}\text { Tabla comparativa de los movimientos } \\
\text { Fora Micarla y Vem pra rua }\end{array}$} \\
\hline Características & Fora Micarla & Vem pra rua \\
\hline $\begin{array}{c}\text { Alcance } \\
\text { de sus acciones }\end{array}$ & Local (Natal, RN) & Nacional (Brasil) \\
\hline $\begin{array}{c}\text { Nivel } \\
\text { de articulación }\end{array}$ & $\begin{array}{c}\text { Espontáneo y con } \\
\text { escasos recursos }\end{array}$ & $\begin{array}{c}\text { Muy articulado } \\
\text { y con altos } \\
\text { recursos }\end{array}$ \\
\hline \multirow{2}{*}{$\begin{array}{c}\text { Estrategia } \\
\text { de medios }\end{array}$} & $\begin{array}{c}\text { Uso de las redes } \\
\text { sociales como } \\
\text { principal vía de } \\
\text { comunicación }\end{array}$ & $\begin{array}{c}\text { Uso de las redes } \\
\text { sociales como } \\
\text { principal vía de } \\
\text { comunicación }\end{array}$ \\
\hline Liderazgo & $\begin{array}{c}\text { Sin liderazgos } \\
\text { de destaque }\end{array}$ & $\begin{array}{c}\text { Lideres definidos, } \\
\text { responsables de la } \\
\text { toma de decisiones }\end{array}$ \\
\hline Renunciar \\
Reivindicaciones & $\begin{array}{c}\text { la corrupción } \\
\text { del gobierno } \\
\text { municipal y sacar } \\
\text { a la intendenta } \\
\text { de su cargo }\end{array}$ & $\begin{array}{c}\text { pero las acciones } \\
\text { más intensas } \\
\text { fueron por el } \\
\text { impeachment } \\
\text { a Dilma Roussef }\end{array}$ \\
\hline
\end{tabular}

Si bien este trabajo no se inscribe en el análisis lingüístico, el marco teórico-metodológico mencionado sirvió como sustento para encontrar las marcas en un escenario discursivo-semántico propiciado por las redes sociales, tanto del Fora Micarla como del Vem pra rua. Con esa observación crítica se logró evidenciar la apelación emocional para movilizar seguidores, el juicio de valor dirigido principalmente a gobernantes, la reivindicación de valores y la 
postura cerrada a posibilidades de negociación. Lo expuesto revela que lógicas y mecanismos de subjetivación análogos pueden permear distintas prácticas ciberactivistas, independientemente de sus objetivos políticos específicos.

Pensar una biopolítica digital, en esa perspectiva, significa ponerse un problema distinto al de cómo usar las redes digitales de forma eficaz para conseguir un determinado objetivo político o lograr la movilización de personas: significa levantar el problema de cómo modificar las lógicas que estructuran a las redes. Lo que aquí se denomina biopolítica digital, en suma, no difiere de la idea guattariana, recogida por Aguiar (2010), de una ecología de lo virtual que funcione como "un dispositivo de creación de nuevos modos de subjetivación" (p. 11), o sea, que produzca "las condiciones de creación y desarrollo de formaciones de subjetividad inusitadas" (Guattari citado en Aguiar, 2010, p. 11).

\section{Referencias}

Aguiar, L. (2010). Comunicação e Ecologia da Mente: possíveis articulações entre crise ambiental e produção de subjetividade. Semiosfera, 10, 01-15.

Bentes, I. (2013). Prefácio. Nós somos a rede social. Malini, F. y Antoun, H. A internet e a rua: ciberativismo e mobilização nas redes sociais(pp. 9-16). Porto Alegre: Sulina.

Castells, M. (2013). Redes de indignação e esperança: movimentos sociais na era da internet (C. A. Medeiros, Trad.). Río de Janeiro: Jorge Zahar.

Cocco, G. (2009). MundoBraz: o devir-Brasil do mundo e o devir-mundo do Brasil. Rio de Janeiro: Record.

Da Silveira, S. (2012). Redes cibernéticas e a reconfiguração da biopolítica. Cocco, G. Y Abbagli, S. (Orgs.). Revolução 2.0 - e a crise do capitalismo global (pp. 281-292). Rio de Janeiro: Garamond.

Da Silveira, S., Braga, S. y Penteado, C. (2014). Cultura, política e ativismo nas redes digitais. San Pablo: Fundação Perseu Abramo.
Deleuze, G. (2015). 0 que é um dispositivo?. Escola Nômade de Filosofia. Recuperado de http://escolanomade. org/2016/02/24/deleuze-o-que-e-um-dispositivo/

Fairclough, N. (2001). Discurso e mudança social. Brasilia: Universidade de Brasilia.

Fairclough, N. (2003). Analysing discourse: textual analysis for social research. Londres/Nueva York: Routledge.

Malini, F. y Antoun, H. (2013). A internet e a rua: ciberativismo e mobilização nas redes sociais. Porto Alegre: Sulina.

Martin, J. R. y White, P. R. R. (2005). The language of evaluation: appraisal in English. Londres: Palgrave.

Morozov, E. (2011). L'ingenuità della rete. II lato oscuro della libertà di internet (M. Renda, Trad.). Turín: Codice.

Negri, A. (1993). A anomalia selvagem. Poder e potência em Spinoza (R. Ramalhete, Trad.). San Pablo: Editora 34.

Negri, A. (2004). Para uma definição ontológica da multidão. Lugar comum, 19-20, 15-26.

Negri, A. (2005). A constituição do comum. Presentado en el II Seminario Internacional Capitalismo Cognitivo - Economia do Conhecimento e a Constituição do Comum. Rio de Janeiro, Brasil.

Negri, A. y Hardt, M. (2005). Multidão. Guerra e democracia na era do Império (C. Marques, Trad.). Rio de Janeiro: Record.

Negri, A. y Hardt, M. (2010). A produção biopolítica. Parente, A. (Org.). Tramas de rede: novas dimensões filosóficas, estéticas e políticas da comunicação (pp. 161-173). Porto Alegre: Sulina.

Padilla, M. (2012). El kit de la lucha en Internet. Madrid: Traficantes de Sueños.

Rüdiger, F. (2011). As teorias da cibercultura. Perspectivas, questões e autores. Porto Alegre: Sulina.

Vem pra rua. (s. f.). Sobre nos. Recuperado de http://www. vemprarua.net/sobre-nos

DOI: http://dx.doi.org/10.22235/d.v0i25.1269 